\title{
Longitudinal analysis of sinus microbiota post endoscopic surgery in patients with cystic fibrosis and chronic rhinosinusitis: a pilot study
}

\author{
Brett Wagner Mackenzie*, Camila Dassi, Anitha Vivekanandan, Melissa Zoing, Richard G. Douglas and \\ Kristi Biswas
}

\begin{abstract}
Background: Cystic fibrosis is a debilitating, autosomal recessive disease which results in chronic upper and lower airway infection and inflammation. In this study, four adult patients presenting with cystic fibrosis and chronic rhinosinusitis were recruited. Culture and molecular techniques were employed to evaluate changes in microbial profiles, host gene expression and antimicrobial resistance (AMR) in the upper respiratory tract over time.

Methods: Swab samples from the sinonasal cavity were collected at the time of surgery and at follow-up clinics at regular time intervals for up to 18 months. Nucleic acids were extracted, and DNA amplicon sequencing was applied to describe bacterial and fungal composition. In parallel, RNA was used to evaluate the expression of 17 AMR genes and two inflammatory markers (interleukins 6 and 8 ) using custom qPCR array cards. Molecular results were compared with routine sinus and sputum culture reports within each patient.

Results: Bacterial amplicon sequencing and swab culture reports from the sinonasal cavity were mostly congruent and relatively stable for each patient across time. The predominant species detected in patients P02 and P04 were Pseudomonas aeruginosa, Staphylococcus aureus in patient P03, and a mixture of Enterobacter and S. aureus in patient P01. Fungal profiles were variable and less subject specific than bacterial communities. Increased expressions of interleukins 6 and 8 were observed in all patients throughout the sampling period compared with other measured genes. The most prevalent AMR gene detected was ampC. However, the prevalence of AMR gene expression was low in all patient samples across varying time-points.
\end{abstract}

Conclusions: We observed a surprising degree of stability of sinonasal microbial composition, and inflammatory and AMR gene expression across all patients post sinus surgery.

Keywords: Cystic fibrosis, Chronic rhinosinusitis, Antimicrobial resistance, Sinonasal microbiota, Cultivation

\section{Background}

Cystic fibrosis (CF) is the most common life-threatening inherited condition in Caucasian populations and results in the build-up of thick mucus, and repeated cycles of airway infection. [1]. Although bacterial lung

*Correspondence: bc.wagner@auckland.ac.nz Department of Surgery, The University of Auckland, 85 Park Road, Grafton, 1023 Auckland, New Zealand infections ultimately shorten the life expectancy in most CF patients, nearly all CF patients also suffer from longterm inflammation of the sinuses, or chronic rhinosinusitis (CRS) [2]. The unified airway theory proposes a bi-directional relationship between the upper and lower airway microbiota [3]. Recent evidence suggests that the sinuses can serve as a reservoir for bacterial pathogens that subsequently colonise the lungs $[4,5]$. Furthermore, medical and surgical management of upper respiratory 
inflammation is associated with improved lower respiratory outcomes [6, 7].

The upper and lower airways of adult CF patients are typically dominated by potentially pathogenic bacteria such as Staphylococcus aureus, Pseudomonas aeruginosa, Haemophilus spp., Streptococcus spp., Achromobacter spp., Burkholderia spp., and Enterobacter spp. [8-12]. Similar bacteria can be detected in the lungs of healthy adults, however, bacterial diversity is significantly increased, meaning more bacterial species are detected, and the dominance of a single species is not observed [13]. When comparing adult CF patients experiencing pulmonary acute exacerbations to those that are clinically stable, the bacterial load of the dominant bacterial pathogen increases [14]. In addition to an increased colonisation of pathogens, the airways of CF patients also have significantly increased expression of inflammatory markers and extensive airway remodelling compared to healthy controls $[15,16]$.

The polymicrobial infections associated with the lower airways of CF patients have been extensively researched [17-20]. However, several aspects of the CF-associated upper airway microbiota, including its temporal stability, relationship to the lower airway microbiota, and contribution to acute exacerbation events, remains less well defined. Recent research suggests that the sinus microbiota in CF-CRS patients are distinct from those patients with idiopathic CRS and are characterized by a significant decrease in overall bacterial diversity and richness accompanied by an increase in bacterial load [10]. Concordant results have also been observed in the lower airways of CF patients when compared with aged-matched, healthy patients [9]. When comparing healthy and idiopathic CRS sinonasal microbial community compositions to patients with CF, significant increases in relative abundance and prevalence of Corynebacterium spp., Anaerococcus spp., and Propionibacterium spp. are observed in the former [10].

Mitigating lung function decline is one of the main goals of CF treatment. Even with the significant improvements in modern treatment, such as ivacaftor, most CF patients will require multiple courses of oral and intravenous antibiotics. As the disease progresses patients often require more intensive antibiotic therapy. This lifelong exposure to antibiotics is associated with the development of antimicrobial resistance (AMR) and a loss of bacterial diversity. An exemplar longitudinal study focusing on the lower airway microbiota in CF patients found that antibiotic use was the most significant driver of reduced bacterial diversity [21].

One recent study suggested that CRS exacerbations may be a precursor to pulmonary exacerbations [22]. CRS exacerbations can be caused by viral or bacterial infections and are characterised by an acute and transient worsening of symptoms [23]. Understanding the composition of the CF-CRS sinonasal microbiota, congruence between cultivation and molecular results, and the accumulation and expression of AMR genes are critical for improving treatment to reduce lung function decline. In our pilot study, we describe the stability of the sinonasal microbiota in four adult CF-CRS patients up to 18 months post sinus surgery. We also measured the expression of inflammatory marker genes and a range of AMR genes. These molecular data were reported in conjunction with patient clinical and culture data for both sputum and sinus swab samples.

\section{Methods}

The objective of this pilot study was to describe the sinonasal microbiota, and host inflammatory and AMR gene expression in adult cystic fibrosis patients post endoscopic sinus surgery during clinical stability. A combination of cultivation and molecular techniques were applied in this investigation.

\section{Patient data and sample collection}

Four subjects undergoing functional endoscopic sinus surgery (FESS) for extensive bilateral CRS were recruited for this study. Patients aged $>18$ years and with a diagnosis of both CRS and CF were included in this study. Patients were diagnosed with CF prior to this study and were subsequently diagnosed with CRS according to the 2012 European Position Paper definition [24]. Three patients were homozygous for $\Delta \mathrm{f} 508$ mutation and one patient was diagnosed with CF based on the evidence of phenotypic disease and sweat chloride test results $>60 \mathrm{mmol} / \mathrm{L}$. Extensive demographic and clinical data were collected from the patients in this study (Table 1), including long-term medications and recent antibiotic prescription data (Additional file 1: Tables S1, S2).

As part of standard clinical care, a nasal swab and sputum sample were collected for routine cultivation analyses at the hospital laboratory. In addition to samples for culture, sterile rayon-tipped swabs (Copan, \#170KS01) were collected under endoscopic guidance from the left and right middle meatuses by a single surgeon for molecular analyses. After collection, swabs were stored in RNAlater ${ }^{\circledR}$ preservative overnight at $4{ }^{\circ} \mathrm{C}$, then transferred to $-80^{\circ} \mathrm{C}$ until processing. Baseline samples were collected during FESS, and follow-up samples were collected in clinic at regular time intervals up to 18 months postoperatively. If a patient required revision FESS, additional samples were collected. 


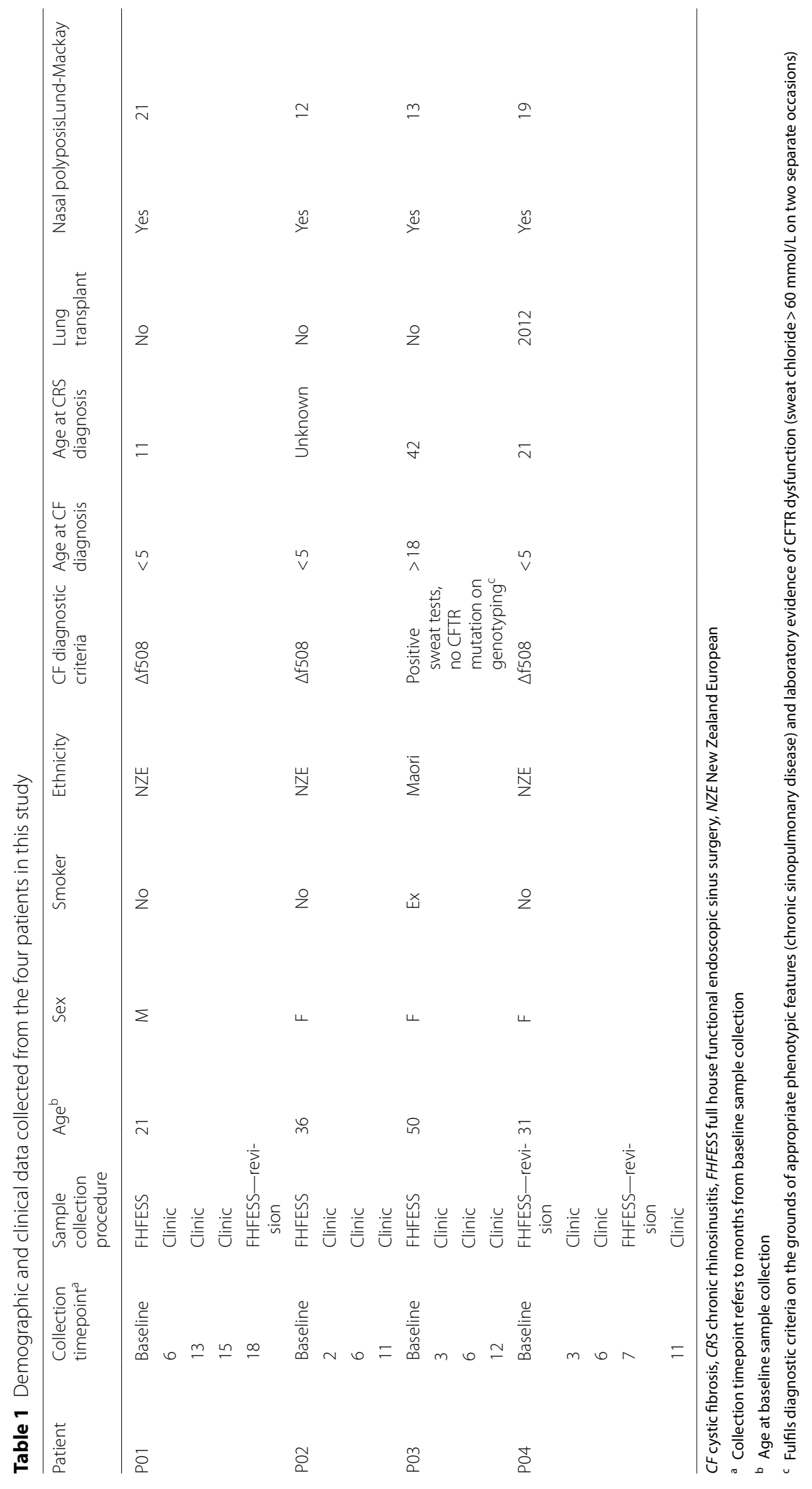




\section{Sample processing for cultivation}

Nasal swabs and sputum samples were processed for routine microbiological culture at Auckland City Hospital LabPLUS laboratory. Relevant pathogens and significant isolates were identified by colony morphology, with further species classification using matrix-assisted laser desorption ionization time-of-flight mass spectrometry (VITEK $^{\circledR}$ MS, Biomerieux). Other groups of organisms that were detected but not identified as clinically relevant included skin flora from nasal swabs, mixed oropharyngeal flora in sputum or nasal swabs, mixed Gram-positive and Gram-negative bacteria. Quantitative assessments of bacterial colonies were not collected. Positively identified colonies were assessed for antibiotic resistance and susceptibility profiles according to EUCAST criteria. Results were interpreted from reports generated by the laboratory.

\section{Sample processing for bacterial and fungal amplicon sequencing}

DNA and RNA were extracted from pairs of sterile rayon-tipped swabs using the Qiagen AllPrep DNA/RNA Mini Kit as previously described [10]. The baseline samples from all four patients and the 7-month post-surgery sample from patient P04 were processed in previous studies [10, 25]. The DNA extracted from these samples were used to extinction and excluded from fungal ITS2 amplicon sequencing.

Extracted DNA was used for PCR amplification and purification of the V3-V4 regions of the bacterial $16 \mathrm{~S}$ rRNA gene and fungal ITS2 as previously described [26]. The V3-V4 primers, including Illumina adaptors in underlined typeface, are as follows: S-D-Bact-0341b-S-17 5'-TCGTCGGCAGCGTCAGATGTGTATAAG AGACAG-CCTACGGGNGGCWGCAG-3' and S-DBact-0785-a-A-21 5'-GTCTCGTGGGCTCGGAGATGT GTATAAGAGACAG-GACTACHVGGGTATCTAATC C-3'. The ITS2 primers were as follows: ITS3 5'-TCG TCGGCAGCGTCAGATGTGTATAAGAGACAG-GCA TCGATGAAGAACGCAGC-3' and ITS4 5'-GTCTCG TGGGCTCGGAGATGTGTATAAGAGACAG-TCC TCCGCTTATTGATATGC-3'. Purified amplicons were sequenced by Auckland Genomics on the Illumina MiSeq using $2 \times 300$ bp paired-end sequencing.

\section{Bioinformatic processing of amplicon data}

Bacterial and fungal amplicon sequencing data were processed using usearch v10.0.240 [27, 28]. Zero-radius operational taxonomic units (zOTUs) of unique biological replicates were generated for both bacterial and fungal data to improve differentiation of closely related sequences. The bacterial (https://github.com/mhog025/
Microbiota-amplicon-bioinformatics/blob/master/Bacte ria_16S) and fungal (https://github.com/mhog025/Micro biota-amplicon-bioinformatics/blob/master/Fungi_ITS) bioinformatic pipelines are available online at GitHub. Briefly, primer sequences were removed, bacterial sequence data were trimmed to $250 \mathrm{bp}$, and the resulting sequences were quality filtered following the parameters outlined in the pipeline. zOTUs were clustered then classified against the SILVA LTP v123 database [29]. Nontarget zOTUs, including those that could not be classified to family-level and sequences comprising $<0.1 \%$ of the total dataset were removed. Data were normalised to an even depth of 5847 sequences per sample.

Raw fungal sequencing data were processed following the parameters outline in the pipeline on GitHub. Fungal zOTUs were clustered then classified using the UNITE UTAX reference database 10.10.2017 [30]. Non-target zOTUs and those classified as Metazoa or Plantae were removed. Sequences comprising $<0.1 \%$ of the total dataset were also removed. Data were normalised to an even depth of 788 sequences per sample.

\section{Real-time PCR for gene expression}

The baseline samples from all four patients and the 7-month post-surgery sample from patient P04 were processed in previous studies $[10,25]$. The RNA extracted from these samples were used to extinction and excluded from real-time PCR (RT-qPCR) gene expression analyses. Input RNA volumes for digestion were standardised to $14 \mu \mathrm{L}$. Prior to reverse transcription of RNA, any genomic DNA remaining in the RNA extracts was digested using DNase I enzyme following the manufacturer's instructions (Invitrogen). The presence of any remaining human or bacterial genomic DNA in the RNA extracts after digestion was determined using PCR. The presence of human DNA was assessed by targeting the human ACTB gene with the $\beta$-actin F (nucleotide positions 393-413) and $\beta$-actin $R$ (nucleotide positions 622-642) primer pair [31, 32]. The presence of bacterial double-stranded DNA was assessed by targeting the V3-V4 regions of the 16S rRNA gene using the S-DBact-0341-b-S-17 and S-D-Bact-0785-a-A-21 primers as stated above. A $1 \mu \mathrm{L}$ input template from each RNA extract was used for PCR. Amplification and thermocycling conditions were as stated above and for both genes. Positive controls comprised either human genomic DNA or $S$. aureus genomic DNA. Negative controls comprised PCR-grade sterile water.

After DNase treatment and assessment of any remaining genomic DNA, the RNA concentration was measured using the NanoDrop ${ }^{\mathrm{TM}}$ spectrophotometer. Samples were standardised to $40 \mathrm{ng}$ before RNA reverse transcription reaction to cDNA using SuperScript ${ }^{\mathrm{TM}}$ IV VILO 
Master Mix following the manufacturer's protocol (ThermoFisher Scientific).

A total of 17 AMR genes, two inflammatory cytokine genes and three housekeeping genes were selected based on previous publications and relevance to CF disease (Additional file 1: Table S3). The expression of each gene was measured in duplicate using a custom TaqMan ${ }^{\circledR}$ array card (ThermoFisher Scientific). RT-qPCR was carried out using the TaqMan ${ }^{\circledR}$ Gene Expression Master Mix on the QuantStudio ${ }^{\mathrm{TM}}$ 12K Flex Real-Time PCR System according to the manufacturer's protocols (ThermoFisher Scientific). The amount of input RNA was standardised so samples and patients could be compared. Raw data were uploaded and analysed using the 'Relative Quantification' app on the Connect Data Analysis online ThermoFisher Scientific Cloud [33]. As there were no healthy control samples from patients without CF or patients that were not prescribed antimicrobials, changes to baseline measurements such as these could not be compared. Therefore, normalisation to the endogenous controls genes $18 S$ (highly expressed), GAPDH (moderately expressed), and HPRT1 (low expression) were used for comparative values within each patient.

\section{Data analyses}

Patient data were collated and reviewed by a clinician. After bioinformatic processing, microbial sequence data were analysed and plotted in $\mathrm{R}$ program version 3.6.1 using the R program 'ggplot2'. For gene expression data, RT-qPCR thresholds were manually set to 0.1 for consistency across targets and array cards. Arithmetic averages of the duplicate $C_{\mathrm{q}}$ values were calculated for each sample. The mean $\Delta \mathrm{C}_{\mathrm{t}}$ represents the mean difference between the target $C_{q}$ values and the endogenous control $\mathrm{C}_{\mathrm{q}}$ values for all the technical replicates for that sample. Values were exported and plotted in R program version 3.6.1.

\section{Results}

Respiratory samples were collected from four patients presenting with CF and CRS at baseline FESS surgery. At least three subsequent samples were collected from each patient in follow-up clinics or revision FESS. Three of the four patients recruited in this study were female, and overall age ranged from 21 to 50 years old at the time of baseline sample collection (Table 1). All patients presented with CRS with nasal polyposis. All four patients were prescribed several long-term medications at the time of recruitment (Additional file 1: Table S1). In the year prior to surgery, patients were prescribed between 3 and 10 antibiotic prescriptions $(\mathrm{P} 01=4, \mathrm{P} 02=7$, $\mathrm{P} 03=10, \mathrm{P} 04=3$ ) (Additional file 1: Table S1). At the time of surgery, P02 was prescribed azithromycin and
P04 was prescribed azithromycin and cotrimoxazole (Additional file 1: Table S2).

\section{Respiratory tract microbiota and AMR determined through cultivation}

Culture of sputum and nasal swabs revealed persistent colonisation of respiratory pathogens in all patients. Often, similar species were reported from sputum and nasal cultivation within the same patient at the same time point (Table 2). Culture reports classified bacteria and fungi to species level in many instances. Staphylococcus aureus, Enterobacter cloacae, and Pseudomonas aeruginosa were the most prevalent CF-associated pathogens detected across all samples. Patient P01 had the most diverse sputum and nasal microbiota as determined through cultivation, while the other three patients were mostly characterised by a single species throughout the sampling period.

Antimicrobial susceptibilities of potential pathogens were conducted in conjunction with cultivation. Along with the highest microbial richness, P01 also had the highest number of observed AMRs in vitro. Both P02 and P04 were characterised by $P$. aeruginosa and reported resistances to gentamicin throughout the sampling period. Patients that were characterised by S. aureus were also typically resistant to $\beta$-lactam antibiotics such as penicillin, amoxycillin, amoxycillin and clavulanate, and flucloxacillin.

\section{Microbial profile determined by molecular methods}

Rarefaction of bacterial sequencing data resulted in 11 zOTUS detected across all samples. Similar to cultivation results the observed richness overall and within each patient was very low ( $\leq 9$ zOTUs) (Fig. 1). Members of the genus Pseudomonas dominated the bacterial community in patients P02 and P04. Sequences assigned to Enterobacteriaceae or Enterobacter were detected in high relative abundances in P01. Patient P01 also had the highest observed richness of all patients in this study (9 zOTUs observed across an 18-month sampling period). Although the bacterial profiles were fairly consistent through time, patients P01 and P02 saw blooms of Staphylococcus zOTUs (Fig. 1a). Patient P03 was characterised by a consistent dominance of Staphylococcus spp. throughout the sampling period.

Rarefaction of fungal sequencing data resulted in 64 zOTUs. Members of the genus Malassezia and unclassified fungal zOTUs were the most prevalent in the dataset, followed by a long tail of low abundance fungal zOTUs (Fig. 1b). Other fungi including zOTUs belonging to Aspergillaceae, Aspergillus, Alternaria, Pleosporales, Dothideomycetes, and Cryptococcus were 
Table 2 Patient sputum and nasal swab cultivation report alongside bacterial 165 rRNA gene sequencing results

\begin{tabular}{|c|c|c|c|c|c|}
\hline Patient & $\begin{array}{l}\text { Collection } \\
\text { timepoint }^{\mathrm{b}}\end{array}$ & Sputum sample & Bacterial 16S rRNA sequencing & Nasal swab & Antimicrobial resistance \\
\hline \multirow[t]{5}{*}{ P01 } & Baseline & $\begin{array}{l}\text { Staphylococcus aureus } \\
\text { Other }^{\mathrm{a}}\end{array}$ & $\begin{array}{l}\text { Enterobacteriaceae, Entero- } \\
\text { bacter, Staphylococcus, } \\
\text { Corynebacterium }\end{array}$ & Other & None assessed \\
\hline & 6 & $\begin{array}{l}\text { Staphylococcus aureus, Morga- } \\
\text { nella morganii, Enterobacter } \\
\text { cloacae } \\
\text { Other }\end{array}$ & $\begin{array}{l}\text { Enterobacteriaceae, Enterobac- } \\
\text { ter, Staphylococcus }\end{array}$ & $\begin{array}{l}\text { Enterobacter cloacae } \\
\text { Other }\end{array}$ & $\begin{array}{l}\text { Amoxycillin, Amoxycillin + cla- } \\
\text { vulanate, cefuroxime }\end{array}$ \\
\hline & 13 & $\begin{array}{l}\text { Staphylococcus aureus, Chry- } \\
\text { seobacterium indologenes } \\
\text { Other }\end{array}$ & $\begin{array}{l}\text { Enterobacteriaceae, Entero- } \\
\text { bacter, Staphylococcus, } \\
\text { Corynebacterium }\end{array}$ & $\begin{array}{l}\text { Staphylococcus aureus } \\
\text { Other }\end{array}$ & Penicillin \\
\hline & 15 & $\begin{array}{l}\text { Staphylococcus aureus, mould } \\
\text { Other }\end{array}$ & $\begin{array}{l}\text { Enterobacteriaceae, Enterobac- } \\
\text { ter, Staphylococcus }\end{array}$ & $\begin{array}{l}\text { Enterobacter cloacae, Staphylo- } \\
\text { coccus aureus }\end{array}$ & $\begin{array}{l}\text { Amoxycillin, cefuroxime, } \\
\text { amoxycillin + clavulanate, } \\
\text { penicillin }\end{array}$ \\
\hline & 18 & $\begin{array}{l}\text { Staphylococcus aureus, mould } \\
\text { Other }\end{array}$ & $\begin{array}{l}\text { Enterobacteriaceae, Enterobac- } \\
\text { ter, Staphylococcus }\end{array}$ & $\begin{array}{l}\text { Staphylococcus aureus, Entero- } \\
\text { bacter cloacae }\end{array}$ & $\begin{array}{l}\text { Penicillin, erythromycin, amoxy } \\
\text { cillin, cefuroxime, amoxycil- } \\
\text { lin + clavulanate }\end{array}$ \\
\hline \multirow[t]{4}{*}{ P02 } & Baseline & $\begin{array}{l}\text { Pseudomonas aeruginosa } \\
\text { Other }\end{array}$ & Staphylococcus, Pseudomonas & $\begin{array}{l}\text { Pseudomonas aeruginosa } \\
\text { Other }\end{array}$ & Gentamicin \\
\hline & 2 & $\begin{array}{l}\text { Pseudomonas aeruginosa } \\
\text { Other }\end{array}$ & Staphylococcus, Pseudomonas & Other & - \\
\hline & 6 & - & Pseudomonas & - & - \\
\hline & 11 & $\begin{array}{l}\text { Pseudomonas aeruginosa } \\
\text { Other }\end{array}$ & $\begin{array}{l}\text { Pseudomonas, Corynebacte- } \\
\text { rium }\end{array}$ & Pseudomonas aeruginosa & Gentamicin \\
\hline \multirow[t]{4}{*}{ P03 } & Baseline & Staphylococcus aureus & Staphylococcus & Staphylococcus aureus & Penicillin, flucloxacillin \\
\hline & 3 & - & $\begin{array}{l}\text { Staphylococcus, Corynebac- } \\
\text { terium }\end{array}$ & - & - \\
\hline & 6 & $\begin{array}{l}\text { Staphylococcus aureus } \\
\text { Other }\end{array}$ & Staphylococcus, Enterobacter & Staphylococcus aureus & Penicillin, flucloxacillin \\
\hline & 12 & $\begin{array}{l}\text { Staphylococcus aureus } \\
\text { Other }\end{array}$ & $\begin{array}{l}\text { Staphylococcus, Enterobacte- } \\
\text { riaceae }\end{array}$ & Staphylococcus aureus & Penicillin, flucloxacillin \\
\hline \multirow[t]{5}{*}{ P04 } & Baseline & Data not collected ${ }^{c}$ & Pseudomonas, Staphylococcus & $\begin{array}{l}\text { Pseudomonas aeruginosa, } \\
\text { Aspergillus fumigatus } \\
\text { Other }\end{array}$ & $\begin{array}{l}\text { Gentamicin, amikacin, cipro- } \\
\text { floxacin }\end{array}$ \\
\hline & 3 & - & Pseudomonas & Pseudomonas aeruginosa & Gentamicin, ciprofloxacin \\
\hline & 6 & - & Pseudomonas & $\begin{array}{l}\text { Pseudomonas aeruginosa } \\
\text { Other }\end{array}$ & Ceftazidime, gentamicin \\
\hline & 7 & - & $\begin{array}{l}\text { Pseudomonas, Staphylococcus, } \\
\text { Corynebacterium }\end{array}$ & $\begin{array}{l}\text { Pseudomonas aeruginosa, } \\
\text { Fusarium solani complex } \\
\text { Other }\end{array}$ & $\begin{array}{l}\text { Gentamicin, amikacin, cipro- } \\
\text { floxacin }\end{array}$ \\
\hline & 11 & & Pseudomonas, Staphylococcus & $\begin{array}{l}\text { Pseudomonas aeruginosa } \\
\text { Other }\end{array}$ & Gentamicin \\
\hline
\end{tabular}

In vitro antimicrobial resistance is noted only for nasal swab isolates. Results from left and right middle meatus swabs for molecular techniques are combined. In vitro antimicrobial resistance profiles from nasal swab bacteria are noted

a 'Other' refers to growth of bacterial colonies that were not considered clinically relevant. This includes mixed oropharyngeal bacteria, mixed Gram-positive and Gram-negative colonies, commensal flora or skin flora. These colonies were not further isolated or identified

b Collection timepoint is given as months since baseline collection

c Sputum samples were not collected from this patient. Analysis of patient records revealed that prior to lung transplantation in 2012 the dominant organisms recovered from sputum were Pseudomonas aeruginosa and Aspergillus fumigatus. Sputum collected post lung transplantation, but prior to this study, cultured Pseudomonas aeruginosa

detected in varying relative abundances across patient samples. We observed no patient-specific fungal fingerprint. Fewer fungal amplicon samples passed quality filtering, which suggests these microbes are less abundant than bacteria.

\section{AMR and inflammatory gene expression}

We observed very low or no expression for the selected AMR genes in this study, suggesting that these genes may not be constitutively expressed or the input concentration of RNA was not high enough for detection. 


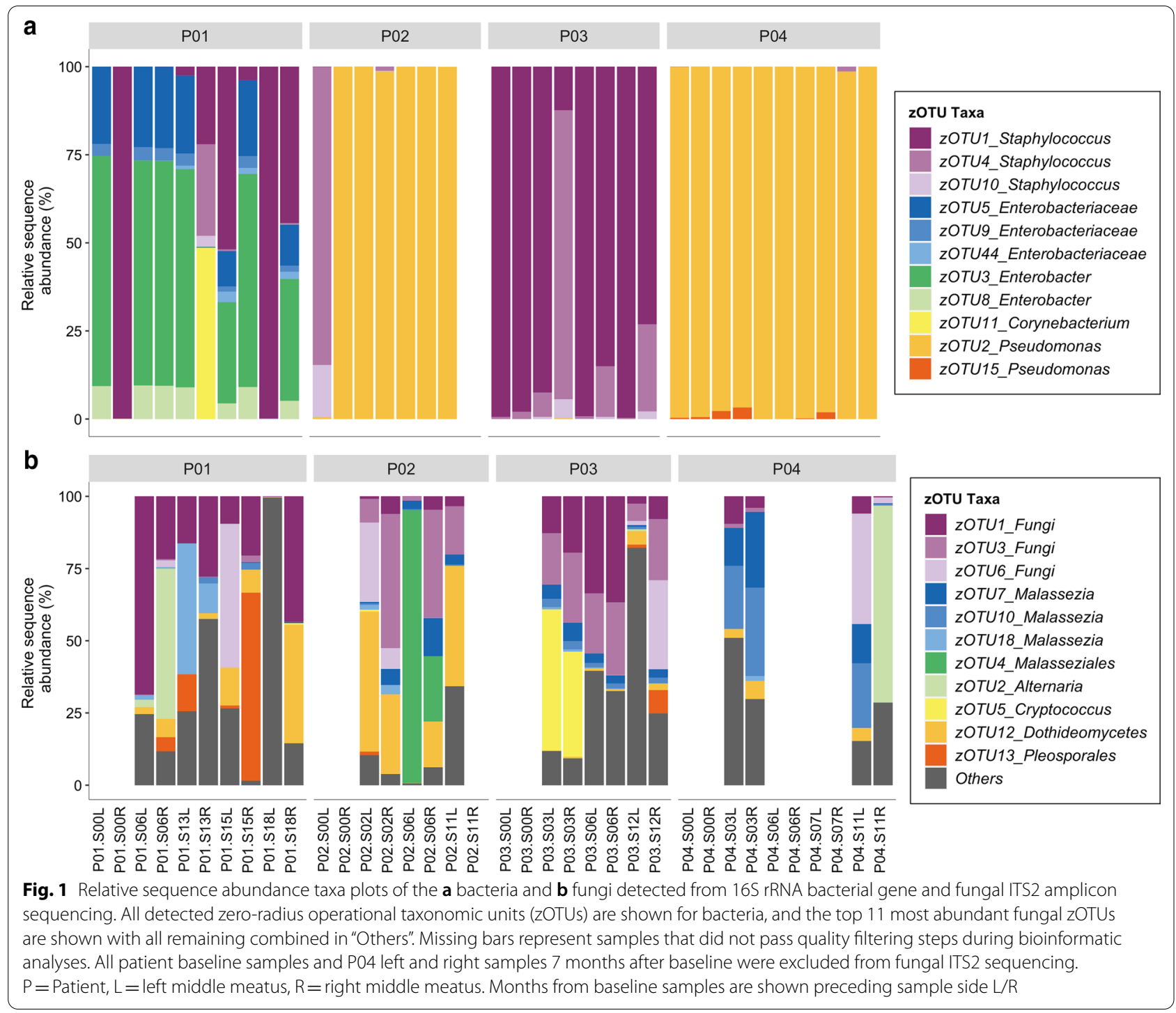

For example, when expression of any AMR genes were detected the raw $C_{t}$ values ranged from 33.1-39.4, and maximum $\mathrm{C}_{\mathrm{t}}$ was 40 . Of the 17 genes measured, $\operatorname{amp} C$, blaVIM2, and blaOXA30 were detected in at least one sample (Fig. 2). Notably, $a m p C$ was the only AMR gene expressed in all four patients in at least one sample. Interestingly, variable expressions were observed through time and between sides of the same patient.

The expression of host inflammatory (IL8, IL6) genes were more prevalent and highly expressed compared with the AMR genes. However, similar to AMR gene expression results, we observed variable expressions of these genes in samples from different sides. IL8 expression was detected in nearly all samples, whereas IL6 expression was inconsistent.

\section{Discussion}

Several longitudinal studies have been published that describe changes in the CF lower airway microbiome over time. Fewer studies have evaluated the longitudinal stability of the upper airway microbiome; however, it would appear that the predominant taxa colonising the airways of adult CF patients tend to exhibit remarkable resilience [21,34-36]. Although some changes may occur during acute exacerbations or treatment, global shifts from these predominant taxa seldom occur in adult CF patients. The results of our study support this observation. 


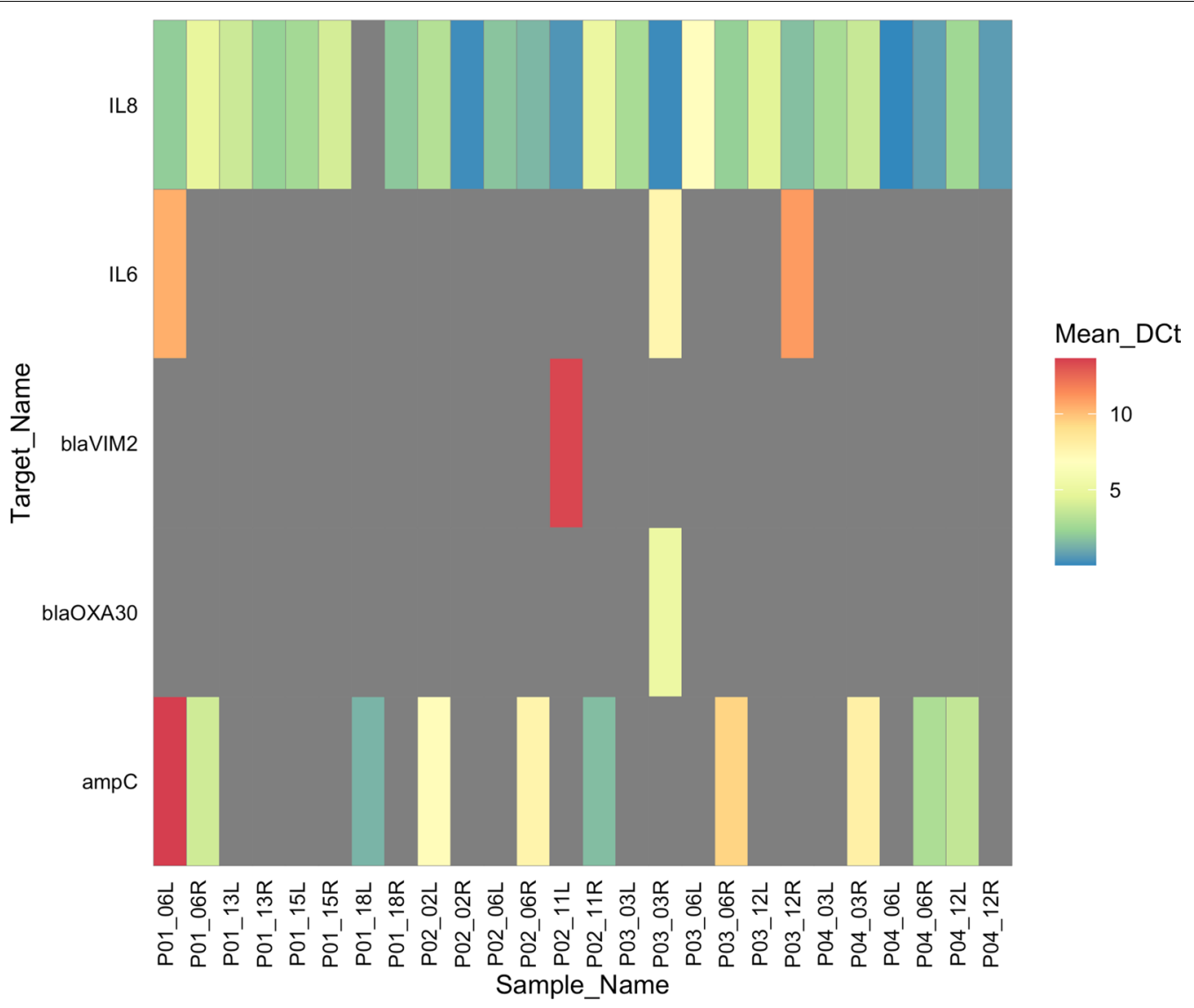

Fig. 2 Heatmap depicting the mean delta $C_{t}\left(\Delta C_{t}\right)$ values of antimicrobial resistance and host inflammatory gene expressions from patient sinus swab samples in this study. Elevated expressions of genes, and therefore lower $\Delta C_{t}$ values are noted in blue colours, and lower expressions of genes are noted in red. Mean $\Delta C_{t}$ values were obtained by calculating the differences between endogenous control genes (18S, GAPDH, HPRT1) and genes of interest. Only those genes which were detected in at least one sample are shown. Samples with no gene expression are shaded in grey. All patient baseline samples and P04 left and right samples 7 months after baseline were excluded from gene expression analyses. Mean_DCt $=$ mean $\Delta C_{t}, P=$ Patient $L=$ left middle meatus, $R=$ right middle meatus. Months from baseline samples are shown preceding sample side $L / R$

\section{Long-term microbial profiles: cultivation versus molecular detection}

Overall, there was substantial congruence between the nasal swab culture and sinus molecular results taken at the same timepoint within patients. Bacterial species grown in culture from nasal swabs were nearly always detected by bacterial sequencing. However, some key differences were noted. Members from the genus Corynebacterium were detected typically in low abundances in the molecular data, however, none were reported in cultivation. This could be because Corynebacterium spp. are typically commensal bacteria, less likely to impact CF disease and are either not reported or targeted for by specific diagnostic culture methods. Nasal swab culture reports mirrored the most abundant organisms detected by bacterial sequencing. Furthermore, sputum culture reported similar results as those from nasal swab cultivation and bacterial sequencing at the same timepoint within patients. A few differences were observed. For example, Morganella morganii and Chryseobacterium indologenes were detected in the sputum of patient P01 but not in nasal swab cultivation. Neither of these organisms were detected in the quality filtered dataset, however, inspection of the pre-filtered zOTU table revealed members from the Morganella family were detected in P01 at the same timepoint. We recommend that futures studies utilising sequencing techniques carefully examine filtering parameters for low abundant taxa, as these low abundant taxa may be clinically relevant.

Fungal growth was rarely reported in these samples, so the possible comparisons to molecular results were few. It is likely that routine microbiological culture techniques do not target fungi, especially if fungal infection is not suspected. Mould was reported in two of the sputum samples from P01 but further taxonomic classification was not given. Aspergillus fumigatus was detected 
in the baseline nasal swabs from P04. Two zOTUs were assigned to family Aspergillaceae and two to genus Aspergillus. These four zOTUs were detected in several samples from P01, P03, and P04. Members from the Fusarium solani complex were reported in culture, however, these were not detected in the molecular dataset.

Fungi are typically detected in the upper and lower airways during health, chronic airway disease, and acute infections $[9,25]$. In health, fungi are likely a transient part of the microbiome and inter-kingdom interactions remain understudied. Fungi have been detected in sinus culture reports from CF patients, but infrequently [37]. A diverse array of fungi have been detected in the CF airways in general, including, Alternaria spp., Cladosporium spp., Malassezia spp., Aspergillus spp., Candida spp., and many others [38, 39]. Similar to potential bacterial pathogens, the presence of fungal isolates does not necessarily infer invasive disease. While bacterial infections often characterise CF lung decline, clinical manifestations associated with fungal detections vary ranging from asymptomatic colonisation to sensitisation, hypersensitivity and invasive disease [39].

\section{Antimicrobial prescription, AMR and host gene expression}

The selection of AMR bacteria is a significant concern for CF patients. Very few studies have investigated the expression of AMR genes in sinus samples from CF patients, and little is known of the stability of these genes in the upper airways. In our study, we measured the expressions of 17 AMR genes and resistance profiles of cultivated pathogens in vitro. Although many of the bacterial isolates were multidrug resistant when tested by antimicrobial diffusion discs in vitro, we did not see high levels of AMR gene expression in situ. One reason could be that the patients in this study were sampled while clinically stable. Another explanation is that the thick mucus in the sinuses of CF patients may reduce the exposure of bacteria to antibiotics and reduce the pressure for microbes to constitutively express AMR genes [40]. Lastly, we hypothesise that elevated expression of other AMR genes may be detected with higher input concentrations of RNA. The comparatively low proportion of bacterial RNA versus higher levels of human gene expression could mask lower levels of bacterial RNA. However, higher input concentrations on our array card in this study would have meant that the detection of highly expressed host genes would have exceeded the detectable range.

The RT-qPCR results showed that the $\operatorname{ampC}$ gene was expressed in low levels in all patients, but at varying timepoints and inconsistently between left and right sinuses. Activation of and mutations within this gene confers resistance to most penicillins, cephalothin, cefazolin, cefoxitin, $\beta$-lactamase inhibitor- $\beta$-lactam combinations, and broad spectrum cephalosporins [41]. Members of Enterobacteriaceae and $P$. aeruginosa are known to carry mutations in this gene. Our bacterial sequencing results and culture reports noted the presence of these organisms, and their suspected AMR activity was confirmed in the in vitro analyses.

The multifaceted approach in this study allows for investigations between cultivated isolate in vitro AMR, in situ expressions of AMR genes, and antimicrobial prescriptions to patients at the time of each sample collection. For example, in P01 at the 6-month sample collection, increased expression of $a m p C$ was detected in the sinuses. The sequencing results suggested bacteria in the Enterobacteriaceae family and Enterobacter spp. dominated the sinuses and this observation was supported by cultivation of Enterobacter cloacae in both the sinuses and sputum. In vitro AMR reports suggests the E. cloacae isolate was resistant to amoxycillin, amoxycillin + clavulanate, and cefuroxime. The expression of ampC is consistent with Enterobacteriaceae bacteria, and the amoxycillin + clavulanate prescribed at the time would induce expression of $a m p C$ [41]. This patient was previously treated with cotrimoxazole, doxycycline and roxithromycin in the year prior to sample collection which are typically effective against Enterobacter spp. At the 13-month timepoint, ampC expression is not detected in the sinuses. The cultivation reports suggested the Enterobacter colonisation cleared, and instead $S$. aureus was cultured and detected in the sequencing. $S$. aureus is not known to have $a m p C$, and no expression was detected. Following on, $a m p C$ expression typically coincided with detection of Enterobacter spp. AmpC is also known to occur in Pseudomonas spp., and in this study we saw expression of $a m p C$ occurring with detection of Pseudomonas in culture and sequencing data in P02 and P04. Specifically, P02 and P04 are prescribed ongoing daily and weekly doses of the macrolide antibiotic azithromycin for treatment of $P$. aeruginosa respiratory exacerbations.

Numerous pro-inflammatory cytokines (IL-1 $\beta$, IL6, IL8, and TNF $\alpha$ ) are elevated in the lower airways of CF patients compared to healthy controls [15]. However, some evidence suggests that the immune response in the nasal mucosa of CF patients is not as severe as that observed in the lower airways [42]. This may partially explain why we observed inconsistent expression of IL6 in the sinus swabs, in contrast to previous studies on the lower airways. Cell culture experiments with nasal epithelial cells from CF patients showed significantly increased levels of IL8 under basal conditions, and even higher expressions when challenged with $P$. aeruginosa [43]. Our results support previous observations of 
consistently elevated expression of IL8. Future studies should compare cytokine expression levels in both the upper and lower airways of the same patients through time.

\section{Study limitations}

This pilot study is limited by the small number of patients and therefore the results may not be broadly applicable to other CF patients. However, extensive collection of patient demographic and clinical data, and the range of culture and molecular techniques applied across several timepoints are a real strength. We observed that microbial and inflammatory gene expression profiles were relatively stable throughout the sampling timepoints, findings which are consistent with previous studies. This stability likely reflects the clinical stability of patients during each sampling timepoint. However, the very different sampling timepoints in our study may impact data analyses and interpretation. Future longitudinal studies should endeavour to sample at regular timepoints as more nuanced changes in the microbiome can be detected. We also recommend that future studies include younger patients to capture the dynamic nature of the upper airway microbiota prior to surgical intervention. Sample collection before, during and after CF and CRS acute exacerbations requiring antibiotic treatment will offer valuable insights into the changes in AMR gene expression.

Our results support the previous observation that molecular methods are more sensitive than culture for detecting microbial communities. However, DNA-based sequencing techniques do not differentiate between actively replicating and dead microbes. Additionally, the strain-level variability in CF patients is high and sequencing such short fragments of the bacterial 16S rRNA gene cannot provide conclusive species- or strain-level taxonomic assignments. We recommend that future studies consider using strain-typing of isolates in order to capture subtle but potentially important variations in bacterial strains. The combination of culture dependent and independent techniques applied in this study can serve as a framework for future longitudinal airway microbiome studies. Collection of additional patient information, such as consumption of non-prescribed medication, including probiotics, could help with interpretation of results in larger studies.

\section{Support for a unified airway microbiome}

Endoscopic sinus surgery may alter the relative abundances of the host's microbial profile, but surgery does not eradicate the microbiota altogether [44]. In a previous study, similar $P$. aeruginosa isolates that colonised the lungs and sinuses of CF patients prior to lung transplantation were later detected in the new grafts [5]. In our study, many of the bacterial profiles were consistent before and after surgery. These results may be a reflection of the advanced stage of disease, but they also lend support to the unified airway theory. Although it is hypothesised that microbes from the upper airways transfer to the lower airways, the direction of translocation has yet to be proven [45].

\section{Conclusions}

Providing comprehensive treatment strategies that target both the upper and lower airways is important for reducing CF morbidity. The study presented here provides a framework for subsequent larger studies that aim to evaluate the role of the upper and lower microbiome during CF. The results of this study advance our understanding of the stability of the upper airway microbiota of $\mathrm{CF}$ patients. These data suggest that the upper airway microbial communities are stable through long periods of time in patients post endoscopic sinus surgery. We observed sustained increased expressions of IL8 and lower, frequent expressions of the AMR gene $a m p C$. Comprehensive longitudinal studies are required to expand upon these observations and provide a solid foundation for assessing the impacts of new gene targeted treatments on the unified airway during CF disease progression.

\section{Abbreviations}

AMR: Antimicrobial resistance; CF: Cystic fibrosis; CRS: Chronic rhinosinusitis; FESS: Functional endoscopic sinus surgery; ITS2: Internal transcribed spacer region 2; PCR: Polymerase chain reaction; 16S rRNA: 165 ribosomal ribonucleic acid; RT-qPCR: Quantitative reverse transcription polymerase chain reaction; zOTU: Zero-radius operational taxonomic unit.

\section{Supplementary Information}

The online version contains supplementary material available at https://doi. org/10.1186/s12931-021-01697-w.

Additional file 1: Table S1. Patient long-term medication and antibiotic prescription history. Table S2. Patient antibiotic prescription at each sampling timepoint. Table S3. A list of the AMR genes, tight junction and inflammatory host genes measured in this study using the custom TaqMan ${ }^{\circledR}$ Gene Expression Assay array card.

\section{Acknowledgements}

The authors thank the patients involved in this study and the generous funding from the Garnett Passe and Rodney Williams Memorial Foundation Charitable Trust.

\section{Authors' contributions}

BWM: Conceptualisation, methodology, investigation, formal analysis, writing - original draft, review and editing, CD: Data curation, AR: Data curation, MZ: Patient recruitment, sample collection, data curation RGD: Supervision, patient recruitment, sample collection, data curation, writing — review and editing, KB: Conceptualisation, methodology, writing —original draft, review and editing. All authors read and approved the final manuscript. 


\section{Funding}

This work was supported by the Garnett Passe and Rodney Williams Memorial Foundation Charitable Trust [Conjoint Grant 37016403].

\section{Availability of data and materials}

Due to the sensitive nature of data, the raw sequencing data associated with this study are available by request from the corresponding author.

\section{Declarations}

\section{Ethics approval and consent to participate}

This study was approved by the New Zealand Health and Disability Ethics Committee (19/NTA/7/AM02), and written informed consent was obtained from all participants.

\section{Consent for publication}

Not applicable.

\section{Competing interests}

The authors declare that they have no competing interests.

Received: 19 October 2020 Accepted: 29 March 2021

Published online: 13 April 2021

\section{References}

1. Sanders DB, Fink AK. Background and epidemiology. Pediatr Clin N Am. 2016;63(4):567-84. https://doi.org/10.1016/j.pcl.2016.04.001.

2. Safi C, Zheng Z, Dimango E, Keating C, Gudis D. Chronic rhinosinusitis in cystic fibrosis: diagnosis and medical management. Med Sci. 2019;7(2):32. https://doi.org/10.3390/medsci7020032.

3. Licari A, Castagnoli R, Denicolò CF, et al. The nose and the lung: united airway disease? Front Pediatr. 2017;5:44. https://doi.org/10.3389/fped. 2017.00044.

4. Fothergill JL, Neill DR, Loman N, et al. Pseudomonas aeruginosa adaptation in the nasopharyngeal reservoir leads to migration and persistence in the lungs. Nat Commun. 2014;5:4780. https://doi.org/10.1038/ncomm s5780.

5. Ciofu O, Johansen HK, Aanaes K, et al. P. aeruginosa in the paranasal sinuses and transplanted lungs have similar adaptive mutations as isolates from chronically infected CF lungs. J Cyst Fibros. 2013;12(6):729-36. https://doi.org/10.1016/j.jcf.2013.02.004.

6. Cheng TZ, Choi KJ, Honeybrook AL, et al. Decreased antibiotic utilization after sinus surgery in cystic fibrosis patients with lung transplantation. Am J Rhinol Allergy. 2019;33(4):354-8. https://doi.org/10.1177/19458 92419830624

7. Khalfoun S, Tumin D, Ghossein M, et al. Improved lung function after sinus surgery in cystic fibrosis patients with moderate obstruction. Otolaryngol Head Neck Surg. 2018;158(2):381-5. https://doi.org/10. 1177/0194599817739284.

8. Lucas SK, Yang R, Dunitz JM, et al. 16S rRNA gene sequencing reveals site-specific signatures of the upper and lower airways of cystic fibrosis patients. J Cyst Fibros. 2018;17(2):204-12. https://doi.org/10.1016/j.jcf. 2017.08.007.

9. Pletcher SD, Goldberg AN, Cope EK. Loss of microbial niche specificity between the upper and lower airways in patients with cystic fibrosis. Laryngoscope. 2019;129(3):544-50. https://doi.org/10.1002/lary.27454.

10. Hoggard M, Biswas K, Zoing M, et al. Evidence of microbiota dysbiosis in chronic rhinosinusitis. Int Forum Allergy Rhinol. 2017;7(3):230-9. https://doi.org/10.1002/alr.21871.

11. Bianconi I, D'Arcangelo S, Esposito A, et al. Persistence and microevolution of Pseudomonas aeruginosa in the cystic fibrosis lung: a singlepatient longitudinal genomic study. Front Microbiol. 2019;9:3242. https://doi.org/10.3389/fmicb.2018.03242.

12. Lim YW, Schmieder R, Haynes M, et al. Metagenomics and metatranscriptomics: windows on CF-associated viral and microbial communities. J Cyst Fibros. 2013;12(2):154-64. https://doi.org/10.1016/j.jcf.2012. 07.009 .
13. Zemanick ET, Wagner BD, Robertson CE, Ahrens RC, Chmiel JF, Clancy $J P$, et al. Airway microbiota across age and disease spectrum in cystic fibrosis. Eur Respir J. 2017;50(5):1-13.

14. Cuthbertson L, Walker AW, Oliver AE, Rogers GB, Rivett DW, Hampton $\mathrm{TH}$, et al. Lung function and microbiota diversity in cystic fibrosis. Microbiome. 2020;8(1):1-13.

15. Eckrich J, Zissler UM, Serve F, et al. Airway inflammation in mild cystic fibrosis. J Cyst Fibros. 2017;16(1):107-15. https://doi.org/10.1016/j.jcf. 2016.05.016.

16. Bonfield TL, Konstan MW, Berger M. Altered respiratory epithelial cell cytokine production in cystic fibrosis. J Allery Clin Immunol. 1999;104(1):72-8. https://doi.org/10.1016/s0091-6749(99)70116-8.

17. Lim YW, Evangelista JS, Schmieder R, et al. Clinical insights from metagenomic analysis of sputum samples from patients with cystic fibrosis. J Clin Microbiol. 2014;52(2):425-37. https://doi.org/10.1128/ JCM.02204-13.

18. Price $\mathrm{KE}$, Hampton $\mathrm{TH}$, Gifford $\mathrm{AH}$, et al. Unique microbial communities persist in individual cystic fibrosis patients throughout a clinical exacerbation. Microbiome. 2013;1(1):27. https://doi.org/10.1186/2049-2618-1-27.

19. Singh PK, Welsh MJ, Schaefer AL, et al. Quorum-sensing signals indicate that cystic fibrosis lungs are infected with bacterial biofilms. Nature. 2000;407(6805):762-4. https://doi.org/10.1038/35037627.

20. Briaud P, Camus L, Bastien S, et al. Coexistence with Pseudomonas aeruginosa alters Staphylococcus aureus transcriptome, antibiotic resistance and internalization into epithelial cells. Sci Rep. 2019;9(1):16564. https://doi. org/10.1038/s41598-019-52975-z.

21. Zhao J, Schloss PD, Kalikin LM, et al. Decade-long bacterial community dynamics in cystic fibrosis airways. Proc Natl Acad Sci (US). 2012;109(15):5809-14. https://doi.org/10.1073/pnas.1120577109.

22. Zemke AC, Nouraie SM, Moore J, et al. Clinical predictors of cystic fibrosis chronic rhinosinusitis severity. Int Forum Allergy Rhinol. 2019;9(7):759-65. https://doi.org/10.1002/alr.22332.

23. Fokkens WJ, Lund VJ, Hopkins C, Hellings PW, Kern R, Reitsma S, et al. European position paper on rhinosinusitis and nasal polyps 2020. Rhinology. 2020;58:82.

24. Fokkens WJ, Lund VJ, Mullol J, et al. EPOS 2012: European position paper on rhinosinusitis and nasal polyps 2012. A summary for otorhinolaryngologists. Rhinology. 2012;50(1):1-12. https://doi.org/10.4193/Rhino50E2.

25. Wagner Mackenzie B, Baker J, Douglas RG, Taylor MW, Biswas K. Detection and quantification of Staphylococcus in chronic rhinosinusitis. Int Forum Allergy Rhinol. 2019;9(12):1462-9.

26. Wagner Mackenzie B, Chang K, Zoing M, Jain R, Hoggard M, Biswas K, et al. Longitudinal study of the bacterial and fungal microbiota in the human sinuses reveals seasonal and annual changes in diversity. Sci Rep. 2019;9(1):17416.

27. Edgar RC. UNOISE2: improved error-correction for Illumina 165 and ITS amplicon sequencing. bioRxiv. 2016;081257. https://doi.org/10.1101/ 081257.

28. Edgar RC, Flyvbjerg $\mathrm{H}$. Error filtering, pair assembly and error correction for next-generation sequencing reads. Bioinformatics. 2015;31(21):347682. https://doi.org/10.1093/bioinformatics/btv401.

29. Yilmaz P, Parfrey LW, Yarza P, et al. The SILVA and "all-species Living Tree Project (LTP)" taxonomic frameworks. Nucleic Acids Res. 2014;42(Database issue):D643-8. https://doi.org/10.1093/nar/gkt1209.

30. Koljalg U, Nilsson RH, Abarenkov K, et al. Towards a unified paradigm for sequence-based identification of fungi. Mol Ecol. 2013;22(21):5271-7. https://doi.org/10.1111/mec.12481.

31. Wang $X$, Seed B. A PCR primer bank for quantitative gene expression analysis. Nucleic Acids Res. 2003;31(24):e154. https://doi.org/10.1093/nar/ gng154.

32. Biswas $K$, Hoggard M, Jain R, et al. The nasal microbiota in health and disease: variation within and between subjects. Front Microbiol. 2015;9:134. https://doi.org/10.3389/fmicb.2015.00134.

33. Applied Biosystems. Applied Biosystems ${ }^{\mathrm{TM}}$ Relative Quantitation Analysis Module USER GUIDE. 2016.

34. Hahn A, Burrell A, Fanous $H$, et al. Antibiotic multidrug resistance in the cystic fibrosis airway microbiome is associated with decreased diversity. Heliyon. 2018;4(9):e00795. https://doi.org/10.1016/j.heliyon.2018.e00795.

35. Bacci G, Taccetti G, Dolce D, et al. Taxonomic variability over functional stability in the microbiome of cystic fibrosis patients chronically infected 
by Pseudomonas aeruginosa. bioRxiv. 2020;609057. https://doi.org/10. 1101/609057.

36. Whelan FJ, Heirali AA, Rossi L, et al. Longitudinal sampling of the lung microbiota in individuals with cystic fibrosis. PLOS ONE. 2017;12(3):e0172811. https://doi.org/10.1371/journal.pone.0172811.

37. Wise SK, Kingdom TT, Mckean $L$, et al. Presence of fungus in sinus cultures of Cystic fibrosis patients. Am J Rhinol. 2005;19(1):47-51.

38. Hong G, Miller HB, Allgood S, Lee R, Lechtzin N, Zhang SX. Use of selective fungal culture media increases rates of detection of fungi in the respiratory tract of cystic fibrosis patients. J Clin Microbiol. 2017;55(4):1122-30.

39. Delfino E, Del Puente F, Briano F, Sepulcri C, Giacobbe DR. Respiratory fungal diseases in adult patients with cystic fibrosis. Clin Med Insights Circ Respir Pulm Med. 2019. https://doi.org/10.1177/1179548419849939.

40. Siu J, Klingler L, Wang Y, Hung CT, Jeong SH, Smith S, et al. Oral antibiotics used in the treatment of chronic rhinosinusitis have limited penetration into the sinonasal mucosa: a randomized trial. Xenobiotica. 2020;50(12):1443-50. https://doi.org/10.1080/00498254.2020.1814973.

41. Jacoby GA. AmpC B-Lactamases. Clin Microbiol Rev. 2009;22(1):161-82. https://doi.org/10.1128/CMR.00036-08.
42. Danel C, Erzurum S, McElvaney N, Crystal R. Quantitative assessment of the epithelial and inflammatory cell populations in large airways of normals and individuals with cystic fibrosis. Am J Respir Crit Care Med. 1996;153:362-8.

43. Carrabino S, Carpani D, Livraghi A, Di Cicco M, Costantini D, Copreni E, et al. Dysregulated interleukin-8 secretion and NF-KB activity in human cystic fibrosis nasal epithelial cells. J Cyst Fibros. 2006;5(2):113-9.

44. Jain R, Hoggard M, Biswas K, Zoing M, Jiang Y, Douglas R. Changes in the bacterial microbiome of patients with chronic rhinosinusitis after endoscopic sinus surgery. Int Forum Allergy Rhinol. 2017;7(1):7-15. https://doi. org/10.1002/alr.21849.

45. Mainz JG, Naehrlich L, Schien M, et al. Concordant genotype of upper and lower airways $P$. aeruginosa and S. aureus isolates in cystic fibrosis. Thorax. 2009;64(6):535-40. https://doi.org/10.1136/thx.2008.104711.

\section{Publisher's Note}

Springer Nature remains neutral with regard to jurisdictional claims in published maps and institutional affiliations.
Ready to submit your research? Choose BMC and benefit from:

- fast, convenient online submission

- thorough peer review by experienced researchers in your field

- rapid publication on acceptance

- support for research data, including large and complex data types

- gold Open Access which fosters wider collaboration and increased citations

- maximum visibility for your research: over $100 \mathrm{M}$ website views per year

At BMC, research is always in progress.

Learn more biomedcentral.com/submissions 